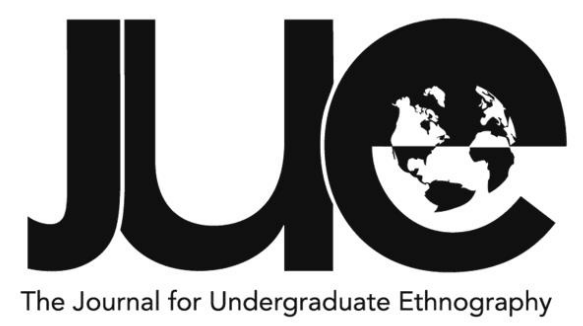

\title{
The Temporality of Identity in Planned Cities: A Case Study of Zhong Xing New Village, Taiwan Michelle Lu
}

University of Pennsylvania-michellu@sas.upenn.edu

\section{ABSTRACT}

In 1957, the Kuomintang (KMT), Chiang Kai-Shek's nationalist government, planned and built Zhong Xing New Village (ZXNV), a garden city, to house the Taiwan Provincial Government. Despite the benefits of public housing, healthcare, and education, ZXNV experienced a two-third drop in population after 1985. The political liberalization and democratization of Taiwan in the 1980s and 1990s led to the reclamation of Taiwanese national identity that rejected the hegemony of the KMT and the physical manifestations of this colonial history, including ZXNV. ZXNV was a utopian ideal constructed during a time of authoritarian rule for a specific political purpose and homogenous population. ZXNV's inability to change its purpose and identity led to its ultimate depopulation. Ethnographic fieldwork reveals the changes in ZXNV's built environment and neighborhood culture influenced by socio-political transformations over the last sixty years. Fourteen interviews were conducted with two generations of ZXNV residents, and archival research reveals the intended design and policies of the city. Key findings include the structural flaws in the city's design, the exposure of political tensions between the national and provincial governments, and the changing national identity of Taiwan due to globalization, all of which led to the ultimate downfall of Zhong Xing New Village.

Keywords: national identity and imagination; politics and space; post-war Taiwan and China; garden cities 
T he story of Zhong Xing New Village, Taiwan is one of space, identity, and politics. Constructed and founded in 1957, Zhong Xing New Village (ZXNV, also romanized as "Chung Hsing New Village") is a planned garden city located in Nantou, central Taiwan. The village was built to serve the Taiwan Provincial Government under the Kuomingtang $(\mathrm{KMT})$, Chiang Kai-Shek's nationalist government that retreated to Taiwan in 1949 following the Chinese Civil War. In 1957, a militarily strategic site at the base of the Hushan mountain range was developed into a garden city with dozens of office buildings and over 3,000 houses. It was home to over 11,000 people.

Since ZXNV's peak in population in the late 1980s, the village has experienced a sharp population decline over the last few decades. This paper explores the structural flaws, such as housing and employment policies, and the tension between neighborhood identity and macro-national identity that led to this decline. The case of ZXNV addresses this question: can a planned city, established to assert a particular political and/or national identity in a colonialist context, survive as its position begins to conflict with the changes in identity and political dominance at the national level? ZXNV provides an excellent site and case study to investigate how a planned urban space shapes and ultimately is shaped by how communities navigate shifting and overlapping ethnic and transnational identities in a global-political context.

Large geopolitical and economic shifts in Taiwan made this garden city impossible to sustain over time. Planned cities are controlled from the top-down, and the garden city model was an astute choice for a governmentcontrolled village. The village identity could be regulated and maintained as those attracted to such a space would then build communities that attract similar people. However, the resulting homogenous identity of community members was temporary as a result of the reclamation of Taiwanese independence and national identity. The seemingly perfect design of the village and the homogeneity in the social and political identity of the villagers could not overcome larger social forces at the national level. The homogenous village identity is notable because of how much it aligned with the KMT's identity, but its temporary nature led to population decline.

Grounding my ethnographic research in Doreen Massey (1992) and Setha Low's (2017) theories of politics and space, I posit that ZXNV's population decline was not only due to the aging population and structural flaws in the original design, but also because the singular purpose of the village, built to serve the provincial government under the KMT, became obsolete through the political evolution and transformation of Taiwan. The village is a time capsule from the 1950s that asserts a particular political identity of a time that existed under the authoritarian KMT regime. The fact that this village did not and could not change structurally with transformations at the national level is ultimately what led to its rapid depopulation, and it shows the limitations of urban planning that is closely connected to time-bound political and cultural assumptions.

\section{Place, Space, and Identity}

To frame this research theoretically within the literature discussing how places carry political history, I turn to Doreen Massey's (1992) article titled Politics and Space/Time and Setha Low's (2017) conceptual frame of the embodied space. Massey's (1992) conceptualization of space as the result of interrelations provides the foundation for the politicization of space. Power dynamics and relationality are vested into space, thus resulting in the asymmetric imbalance of power.

Space is not a "flat" surface in that sense because the social relations which create it are themselves dynamic by their very nature ... It is not the "slice through time" which should be the dominant thought but the simultaneous coexistence of social 
relations that cannot be conceptualized as other than dynamic. Moreover, and again as a result of the fact that it is conceptualized as created out of social relations, space is by its very nature full of power and symbolism, a complex web of relations of domination and subordination, of solidarity and cooperation. (Massey 1992, 81)

Space cannot be devoid of power, as "it is not that the interrelations between objects occur in space and time; it is these relationships themselves which create/define space and time" (Massey 1992, 79). Thus, it is impossible to study the spatial environment of ZXNV without considering the full impact of the KMT regime. As space is created out of interrelations, such a foundation demands inquiry into the nature of these relationships and their positionality with respect to each other. These relationships result in the asymmetry/symmetry of power on an individual level, between waishengren (Chinese immigrants who arrived in Taiwan after 1949) and benshengren (residents with familial roots in Taiwan prior to 1949), at a national level with the KMT regime, and at a global level with Taiwan in the context of globalization. The population decline of ZXNV is wholly related to geopolitical shifts in Taiwan's position in the world. "[T] he spatial spread of social relations can be intimately local or expansively global, or anything in between. Their spatial extent and form also changes over time ... there is no getting away from the fact that the social is inexorably also spatial" (Massey 1992, 80).

This case study of Zhong Xing New Village shows that space cannot be a-temporal or static. The very passage of time resulted in the deterioration of the space itself and the identity that constructed that space as the web of relations comprising ZXNV dissolved and disappeared. Low (2017) and Massey (1992) both "view space and place as always under construction, produced by global to local interactions and constituted by multiple bodies, collectivities and trajectories. In this sense, considerations of space and place shake up the way political questions are formulated" (Low 2017, 211). Low's conceptual frame of the "embodied space" further builds upon the imagination of space and place as a continuum of global to intimate interrelations.
The conceptual frame of "embodied space" integrates body/space/culture and connects microanalyses of individual bodies and place -making to macroanalyses of social, economic and political forces ... The addition of the idea that embodied spaces have "trajectories" as well as time- and spacespecific goals and intentions that are personally, culturally and politically directed brings greater agency and an appreciation of power dynamics to the theorization of individual and collective bodies and their movements ... The conceptual lens that views space as always embodied offers a different approach to the ethnography of space and place by considering human and nonhuman "bodies" as simultaneous spaces as well as producers and products of space. (107)

In other words, viewing space as embodied means the presence and/or absence of a certain demographic embodies the social, economic, and political forces at a certain time and place. As such, KMT ideology was manifested not only in the built environment but also in the people who lived in ZXNV. Because of this, ethnography, and specifically interview-based research, is particularly wellsuited for a case study that uses the lens of embodied space. This village was a "welcoming" and "inviting" space to some, but not to all. The decline in the number of bodies over time reflects the slow decline of the KMT regime and ideology. However, following the complete defunding of the provincial government in 1997, those who chose to stay continued to embody the political legacy of a bygone era in a space that embodies an outdated ideology. In ZXNV, there is an absence of subversive uses of space that contradict the original purpose of its designers, which is distinct from the ethnographic case studies that Low (2017) references through the conceptual frame of the embodied space. However, the continued occupation of this space by older residents is, in a way, a subversion of the dominant national identity in Taiwan today. 
Garden Cities and National Identity

Ebenezer Howard's (1902) book, Garden Cities of To-Morrow, lays the foundation for the garden city as a planned community grounded in the fundamental belief that "town and country must be married, and out of this joyous union will spring ... a new civilization" (10). Howard originally demarcated the ideal city to be 1,000 to 6,000 acres in size and serve 30,000 to 32,000 people, expecting the communities to be socially, politically, and economically selfsufficient. The great degree of cooperation required by such a plan would result in a population bound together by shared community identity in a particular space.

I view the design and construction of ZXNV as an unspoken, unofficial statement from the KMT regime with the intent to formulate identity at the state level. The complete regulation of this village can "help the state to create a favoured ideology, reinforce rulingclass-selected values, maintain control, increase cultural capital value, and thus ensure the success of this (cultural and political) 'hegemony'"' (Chang 2004, 2).

Understanding identity and belonging can pose many challenges, particularly in discussions of national identity. In Taiwan, national identity is particularly fraught due to its history. National identity can be defined as the relationship between people and the state. Alternatively, Benedict Anderson (1983) writes that the nation is "an imagined political community - and imagined as both inherently limited and sovereign" (49). The nation is an imaginative construct that has to be constantly realized or reproduced for it to continue existing. This identity is bound together by a series of common events that allow people to relate to one another on a historical level as well as an ethnic and cultural level. Power dynamics shape identity, and powerful institutions are often able to dictate what an identity is altogether.

\section{Political Evolution and National Identity in Taiwan}

It is important to place the development and construction of Zhong Xing New Village in the context of Taiwan's history. I will offer a brief overview of the Chinese Civil War that led to the KMT's retreat to Taiwan, the history of martial law under the KMT, and a discussion of how politics and national identity have evolved in the last three decades. The existing literature on the transformation of national identity in Taiwan is largely focused on the macro-level social change of changes in electoral behavior in more recent history.

\section{Chinese Civil War}

April 12th, 1927 marks the beginning of a formal civil war between the KMT, led by Chiang Kai-Shek, and the Chinese Communist Party, led by Mao Ze-Dong. On December 9th, 1949, Chiang Kai-Shek fled with thousands of his supporters to reestablish what he believed to be the Republic of China (ROC) in Taipei. The $\mathrm{ROC}$, led by Chiang and the KMT, continued to claim sovereignty over all of "China," which was understood at the time to be mainland China, Taiwan, Outer Mongolia, and other areas. In contrast, the Communist People's Republic of China (PRC) claimed to be the only China, which included Taiwan (Schubert 2012).

\section{Era of Martial Law}

Martial law became the foundation for suppressing communist and Taiwan independence activities in Taiwan, which was first enacted by the KMT in 1949 following the "228 Incident." The "228 Incident" started on February 27, 1947 with the arrest of a cigarette vendor by the KMT-controlled Tobacco Monopoly Bureau, which led to mass protests on February 28, 1947 that lasted for a week and resulted in thousands of civilian deaths (Shattuck 2017). A series of regulations were established, including laws that denied the right of assembly, free speech, and publication in Taiwanese Hokkien, a language spoken by $70 \%$ of the native population. Newspapers were commonly asked to run propaganda articles or to make editorial changes to suit the government's needs. In the 1950s and 1960s, "there were only 31 newspapers, 15 of which were owned by either the KMT, the government, or the military" (ChinatownConnection.com 2007). Under martial law, the formation of any new political parties, especially dissident ones, was prohibited. This period of suppression that would last until the lifting of martial law in 1987 
is also known as "White Terror" (Shattuck 2017; ChinatownConnection.com 2007).

\section{Democratization and Taiwanization in the 1980s}

The indigenization of Taiwanese culture and politics in the past three decades began as a literary movement in which fictional tales reflecting local conditions gained ascendency over the stories of the hegemonic KMT. In the late 1980s and early 1990s, indigenization

(bentuhua，本土化運動), also known as "Taiwanization," developed hand in hand with protests for democracy, social justice, and ethnic equality as Taiwan was also brought into a web of other countries through globalization (Makeham and Hsiau 2005; Chang 2017; Tseng 2016; Stockton 2002; Chu and Lin 2001). "In 1987, the lifting of martial law formally set off the process of indigeni[z]ation and democrati[z] ation. The emphasis in cultural policy shifted from traditional Chinese to contemporary Taiwanese" (Chang 2004, 3). Taiwanization led to the exclusion of the waishengren war migrants, who were commonly referred to as "privileged outsiders" (Hsuan and Chang 2010, 3).

After Chiang Kai-Shek died in 1975, he was succeeded by his Vice-President, Yen Chia-Kan, and then by Chiang Ching-Kuo, Chaing KaiShek's son. During Chiang Ching-Kuo's presidency from 1978 to 1988, the Taiwanese political system saw gradual liberalization. Upon the lifting of martial law in 1987, the Democratic Progressive Party (DPP) was formed in opposition to the Kuomingtang. In 1988, Lee Teng-Hui became the first Taiwanese-born president in office. Until the first election by popular vote in 1996, all previous presidents had been appointed by the KMT. Since 1996, the DPP's popularity has skyrocketed following the election of Chen Shui-Bian in 2000, the first DPP president who marked the end of the KMT's dominance (Chang 2004, 4, 14). "The structural symbiosis between party and state was as much a source of strength as a root of vulnerability for the KMT regime" (Chu and Lin 2001, 118). The DPP's rise in popularity was partly inspired by the changing national identity in Taiwan, which had a direct impact on reducing the power of the KMT.
The political liberalization and democratization of Taiwan in the 1980s and 1990s led to the reclamation of Taiwanese national identity, which rejected the hegemony of the KMT and the physical manifestations of this colonial history, including Zhong Xing New Village. This article will draw upon the existing literature on national identity to contextualize and explore how this meticulously planned and overdesigned garden city experienced such a dramatic decline in population and purpose.

\section{The Historical Context of Zhong Xing New Village}

When the Kuomintang retreated to Taiwan in 1949, they believed that the KMT was the sole legitimate government of China. "Before democratization beginning in the 1980s, identity construct in the Taiwanese society was conditioned upon one political goal ... reunification was one ultimate goal across the strait, there was only one China in the world, which was the Republic of China" (Tseng 2016, 230). It was under the assumption of "One China" that Zhong Xing New Village was constructed.

ZXNV was designed as the Provincial Government headquarters, which was a strategy rooted in political and military conservatism revealing a rash and haphazard decision to exercise power and control space. At first, the village was just a network of office buildings with no place for communal life (Chang 2017, 123). In response to this drab and dreary working environment, the Kuomintang recognized the need to build a community, thus turning to a meticulously designed garden city. And yet, the original "One China" philosophy still lurked. The village's design reflects this dual goal of creating a meaningful, communityoriented village that was not designed to last for multiple generations. This tension led to design flaws that contributed to the village's ultimate decline.

Today, Zhong Xing New Village is like a time capsule from the 1950s. To make ZXNV truly a garden city, it became home to 28,742 trees and a 3:1 tree to person ratio. The village is organized into three smaller districts that each has its own marketplace, elementary-middle school, and community center. The town hall is 
in the middle of the village and is located adjacent to the track and across the street from the library, post office, police headquarters, and ZXNV's high school. The office spaces are concentrated, and the houses are arranged in a linear fashion on cul-de-sacs that branch off of main roads. Over 4,000 houses were constructed and arranged so that the commute by foot to the nearest school or market is less than 10 minutes.

Despite the careful planning, all three districts have experienced a steep decline in population over the last 30 years since the early 1990s, as illustrated in figures 5 and 6 . The population dropped from a peak of 11,000 in the early 1980 s to just under 4,000 in 2018 , a decrease of $64 \%$.
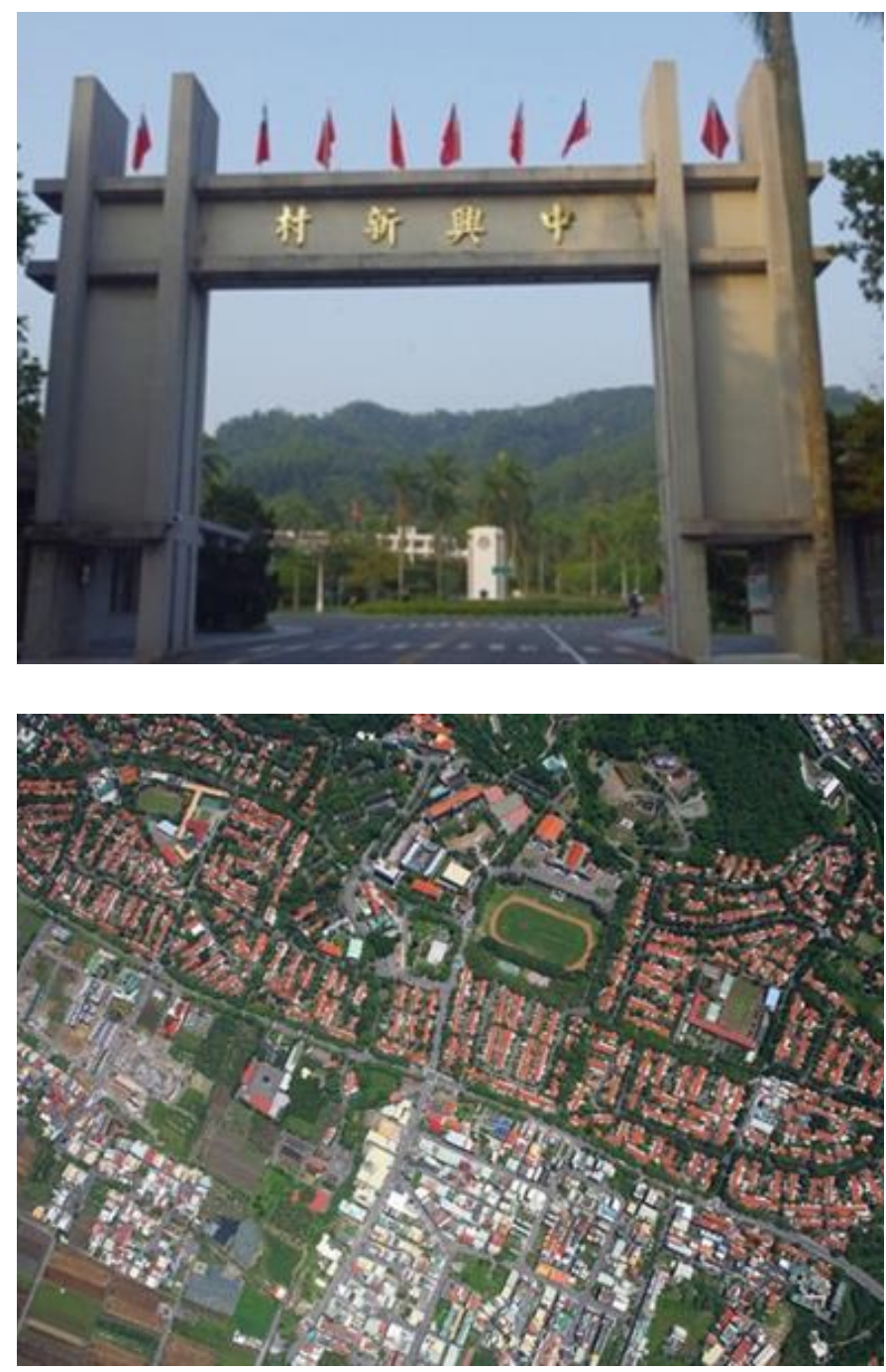

A set of structural flaws and overdeterminism in the design of ZXNV contributed to this population decline. Because the government did not expect and plan for ZXNV to have a multigenerational lifespan, its commercial and employment markets were insufficiently designed to accommodate a growth in population. Firstly, the commercial markets in the village are not staffed by village residents. As the primary criteria for being able to live in the village is being a civil servant and employee of the provincial government, all of the "private sector" jobs in the retail market are only available to those who live outside of the village. The markets cannot grow with demand because there is a physical limit on the amount of commercial and retail space available. Thus, the economy is both physically and legally
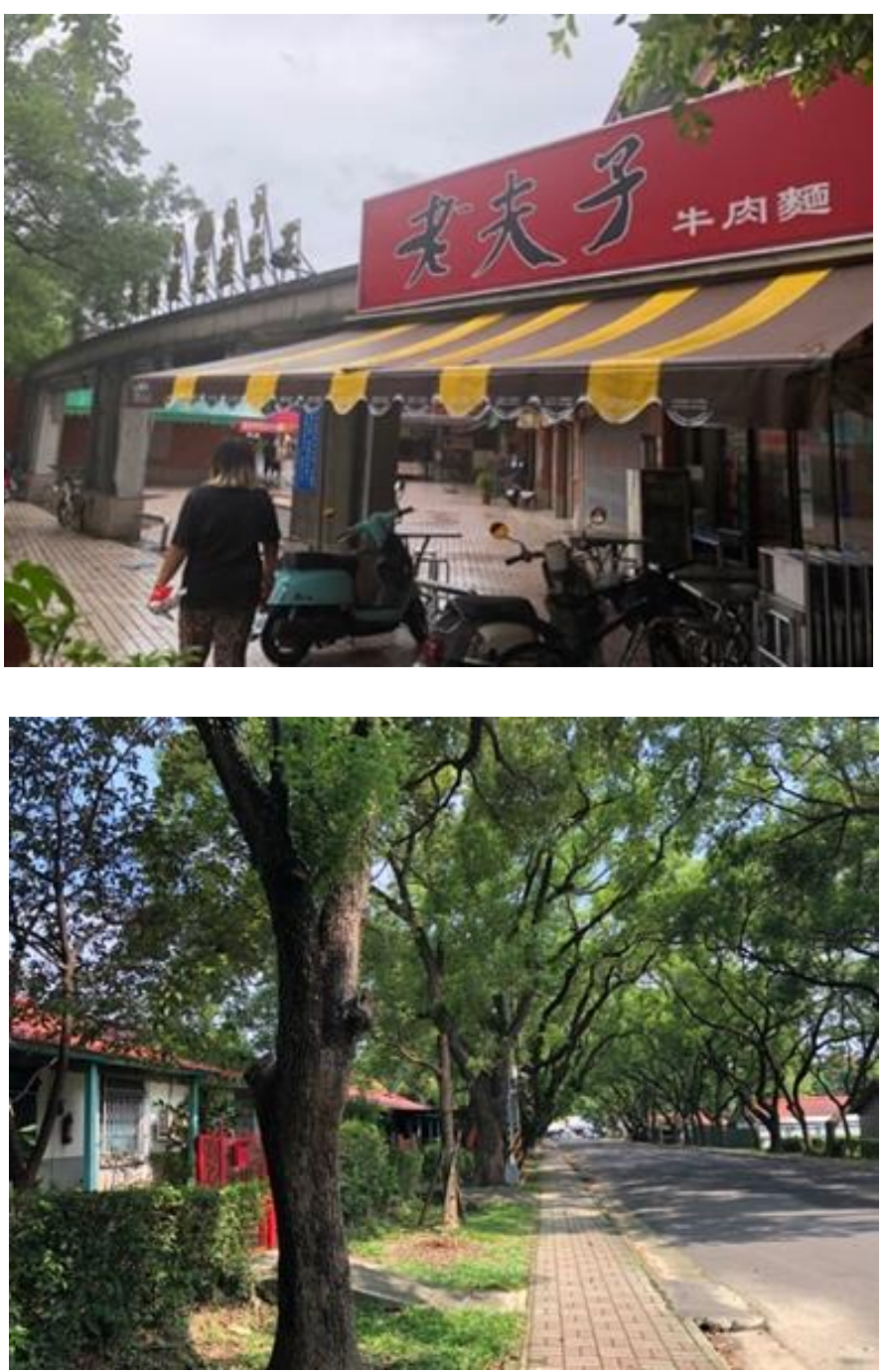

Figures 1-4: Images of Zhong Xing New Village.

Figure 1 (top left): ZXNV Village Gate (Source: Zhong Xing New Village Travel Guide); Figure 2 (top right): ZXNV Market in District 2 (photo by author, 2019); Figure 3 (bottom right): Zhong Zhen Road in ZXNV (Photo by author, 2019); Figure 4 (bottom left): Aerial photo of ZXNV (Source: Google Image Search) 
constrained from growing. This is also mirrored in the public-sector employment market. Since the Provincial Government was headquartered in ZXNV, many of the country's key departments were located in the village, including the Department of Soil and Water Conservancy, the Tax Bureau, and the Department of Ground Transportation, among others.

To qualify to live in the village, one must be an employee of the provincial government. Most of the government employees had moved to the village in their late twenties to early thirties, which meant that they would be expected to work for at least another 35 years, past the point at which many of their children would also be seeking employment. Thus, the job market of ZXNV could not accommodate the second generation who had grown up in the village and were excluded from working in the village. This exclusion was further exacerbated by the strict regulations that were placed on the allotment of public dormitory housing. One key policy prohibits first-generation employees from passing down their houses to their children.

Because these structural flaws have not been changed, ZXNV can be seen as a critique of overdesigned (politically, economically, and socially) spaces that cannot change with time. This village was designed for a homogenous population of the first generation who supported the KMT during its authoritarian regime, but neither this population nor the KMT exist in the same way anymore. Even the most well-thought-out utopian designs cannot overcome larger macroeconomic social forces that have transformed the nation. The planned city was a structurally flawed space that served a specific, homogenous population for a specific time that has since been gone. My paper presents primary source data on how the misalignment of ZXNV's identity with national Taiwanese identity ultimately led to the village's death.

\section{Methodology}

The methodology can be broken down into historical and archival research, ethnography, and interviews. Firstly, archival research on the history and context of ZXNV provided the necessary background on the policies that were at the foundation of the city's design. I utilized census data to track demographic changes over time, looking at both population change and average age. However, the government materials did not provide a holistic account of national identity and how it has changed with time. Thus, I turned to participant observation and interviews as fundamental qualitative sources.

Ethnographic fieldwork revealed the changes in the built environment and neighborhood culture as influenced by socio-political transformations over the last sixty years. I was particularly interested in the languages spoken in different parts of the village and the movements and routines of study participants as well as their social networks. I observed six villagers in Taiwan over the course of two weeks to learn about their daily routines, social communities, and personal values and culture. This participant observation revealed the state of the dominant identity in the village today.

The majority of the data collected and used in this project came from fourteen in-depth semi-structured interviews that I conducted
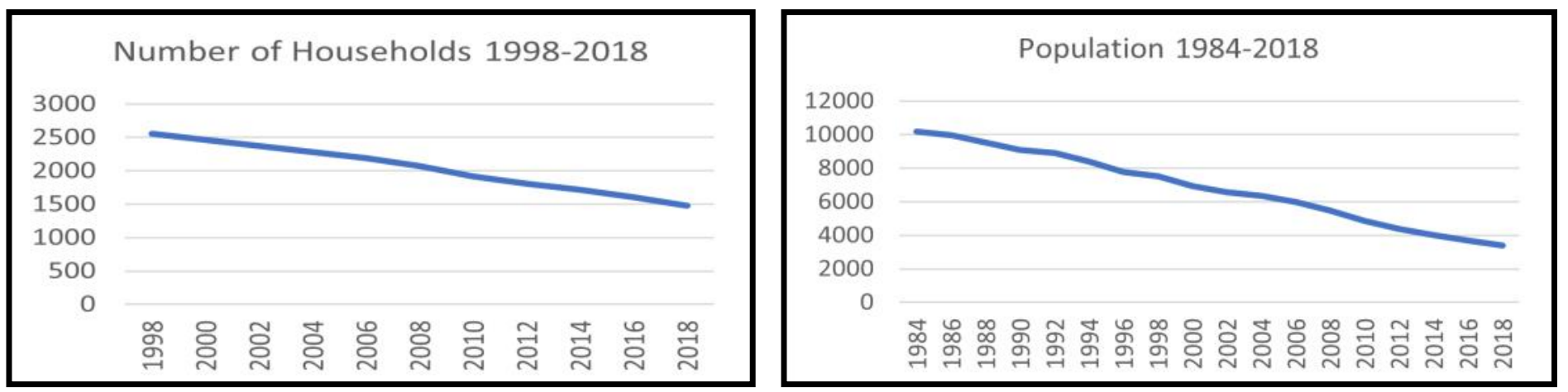

Figures 5-6: Graphs illustrating Zhong Xing New Village's decline in number of households and population. Source: Nantou City Household Registration Office, Nantou County. 
with two generations of interviewees. During the interviews, I asked short biographical questions as well as more in-depth questions about personal history, culture, and values. I wanted to learn the interviewees' motivations for either living in or leaving the village and how the village has shaped their political beliefs and personal identity. I conducted eight interviews in Taiwan and six in the United States, and I spoke with seven people from each generation, which was vital to understanding how identity differed between the two generations. The first generation featured people who chose to move to the village as young adults and decided to start their careers and families there. The second generation included those who were raised in the village but chose to move out in pursuit of other opportunities. This primary source data reveals how the villagers themselves identified with the village. The goal of this design was to illuminate the culture and identity separating the two generations. Given that the first generation arrived in the village as KMT employees at the peak of KMT dominance, this identity can be used as a proxy for understanding what the national identity was like in the 1950s and 60s under the rule of the $\mathrm{KMT}$. All names have been changed to protect interviewees' identities.

I present my findings and analysis in the following three parts: (1) Zhong Xing New Village's First Generation, (2) Zhong Xing New Village's Second Generation, and (3) What Happened to Zhong Xing New Village? The first two parts are further subdivided into sections on goals and aspirations, language and culture, and political belonging.

\section{Part 1: Zhong Xing New Village's First Generation}

In the village's first twenty-or-so years (19571980), the garden city design was effective. By effective, I mean that the villagers were employed where they were assigned to work, they shopped in the markets in their respective housing districts, they lived in houses that were assigned to them, and they used the community centers for public gatherings and recreational activities. The efficacy of ZXNV's design during these first few years was undoubtedly linked to the alignment of the first generation's identity and goals with the original goals of the village and of the KMT during this time.

\section{Building the First-Generation Identity: Goals and Aspirations}

At this time, it is important to outline the initial goals of the first generation as ZXNV's identity is shaped by their vision and purpose for the village. The first generation was primarily focused on jobs, community involvement, and political belonging. Ms. Lee, Ms. Wang, and Ms. Zhang are three interviewees from the first generation whose experiences mirror this identity and culture.

Ms. Lee moved to ZXNV in 1959. She worked in the village hospital in the maternity ward and soon became the head nurse at the hospital. Having grown up in a traditional family with limited opportunities for girls, she was not allowed to finish high school because her parents wanted to save the money for her brother's education, even though she was at the top of her class all throughout grammar school. Thus, she greatly appreciated the freedom and social mobility that was unique to ZXNV, which empowered her to become the head nurse at the hospital. She would not have been able to work in this sort of position elsewhere in Taiwan. She spoke remarkably affectionately and appreciatively of the village and said that it was and always will be her home (C. Lee, interview, August 19, 2019).

Ms. Wang came to ZXNV in 1966 with her husband, and she worked at the library. She was the right-hand woman to the head of the library and was given a lot of responsibility from the start of her career. Even as the library's leadership overturned several times throughout her career, she was the one stable employee who was the foundation of the library. After leaving the library in 1985, she planned community events for the village and coached the tennis team. She also worked at the Tax Bureau, the village government headquarters, and at one of the elementary schools before retiring in 2000 . She has thought about leaving ZXNV several times, but despite her family living elsewhere, she cannot seem to part with her life in the village (K. Wang, interview, August 17, 2019). 
Ms. Zhang moved to the village in 1960 with her husband, who worked in the Soil and Water Conservancy department. She obtained her teaching certificate in Taipei before moving to ZXNV and held a position as a teacher at the local elementary school. Teachers are like celebrities in the village, and to this day, she is greeted as "Zhang Lao Shi," meaning Teacher Zhang, despite having been retired for more than twenty years. She contributed hours of teaching time, trained new teachers, led recreational programs with the children, and was the matriarch of her neighborhood block (S. Zhang, interview, August 6, 2019).

Ms. Lee and Ms. Wang's experiences in particular reflect the great amount of mobility for the first generation that was only available at this time in the village. The rest of Taiwan had not yet modernized, and "professional jobs" were hard to come by. Many of the women interviewees also cited sexism as one of the many reasons why employment was hard to find outside of the village.

For Ms. Lee, Ms. Wang, and Ms. Zhang, their daily routines have not changed much in the sixty years that they have lived in ZXNV. Ms. Zhang, for example, begins each day with a trip to the once-bustling marketplace in her district where she buys soymilk, youtiao, and sweet Taiwanese pineapples from the same vendors that she has been patronizing since the 1960s. She no longer teaches at the elementary school but now spends her day preparing groceries and meals for her husband and neighbors. After a mid-afternoon nap, she goes for a walk around the track or plays a few heated rounds of mahjong with friends. Her daily routine that has stayed consistent over the decades is an example of how a body and its relationships can embody a bygone era, which it continues to reproduce every day. For her, many parts of her lifestyle have not changed, and her community is very much alive; however, she feels a profound sadness when she hears of residents moving out or passing away and their houses boarded up and left to decay. Ms. Zhang's block used to be a lively and crowded cul-de-sac, home to a dozen families. Now, only two of the twelve houses remain occupied. The rest are decaying behind overgrown trees and rusted fences. This slow decay of the built environment is yet another reminder of the slow disinvestment that has haunted ZXNV over the last few decades that mirrors the decay of the KMT regime and embodies the people's new relationship to the KMT and the KMT's new relationship to the people and to political power.

These interviewees are just a few of the 5,000 original residents who built the community of 11,000 (at its peak) from the ground up and who built a life in and, more specifically, defined the identity of the village. Each of these members of the first generation initially came to the village for different reasons-some came as a result of marriage, others in search of employment opportunities. However, they were all primarily focused on jobs, community involvement, and political belonging. These three "goals" of the first generation became crucial to the village identity and were not similarly reflected in the experiences of the second generation. All of these first-generation interviewees moved to Taiwan after 1949 with the retreat of the Kuomingtang, and thus they also reflect the language, culture, and politics of the KMT, which I will discuss in the next section.

\section{Building the First-Generation Identity: Language and Culture}

The culture of ZXNV is most firmly defined by it being a stronghold for waishengren (外省人), meaning people who arrived in Taiwan after 1949 as a result of the retreat of the Kuomingtang. Waishengren, literally meaning outsiders, were often seen as colonists and the "elite" that had interfered and intruded into indigenous Taiwanese society. Waishengren are identifiable as many of them do not speak Taiwanese. This linguistic difference is a telltale sign of being an outsider, and waishengren are rarely accepted as being fully Taiwanese. All of the waishengren who were interviewed for this project identified as either Chinese or ChineseTaiwanese, and none identified as strictly Taiwanese. ZXNV is unique in that it brought together people from all provinces of China and created a space for communication solely in Mandarin. In fact, during the era of martial law, Taiwanese dialects were forbidden in ZXNV, and those caught speaking them would be fined (S. Pan, interview, September 4, 2019). Most firstgeneration interviewees only spoke Mandarin, as they were part of the generation that had 
lived almost half of their lives in China. Many second-generation interviewees also spoke Taiwanese, as most felt like it was necessary outside of ZXNV.

The linguistic differences and tension between the Chinese and the Taiwanese aspects of ZXNV and the rest of Taiwan is at the core of the political issues that ultimately had the biggest influence on the village's rapid decline post-1998. The villagers were bound by their shared waishengren identity in addition to sharing the same employer. Their waishengren identity became more important as proChinese residents became increasingly ostracized in the recent decades as a result of Taiwanization. Within the borders of the village, over $80 \%$ of the population was colloquially known to be waishengren (S. Pan, interview, September 4, 2019). One interviewee identifies as benshengren, a label that represents those who came to Taiwan before the KMT's arrival in 1949. There was tension and strain between the waishengren and benshengren throughout Taiwan at this time. However, in ZXNV, the other $20 \%$ of villagers were benshengren, and they

were all educated and worked in the government, so it wasn't really weird between the two groups. There was harmony at ZXNV, no argument or fight here. My parents' friends are all waishengren, same thing with my friends, but no discrimination between the two. But outside of ZXNV, people feel much more strongly about it. ZXNV is protected and its history is so different from other parts of Taiwan because the KMT has $100 \%$ of control here. (S. Pan, interview, September 4, 2019)

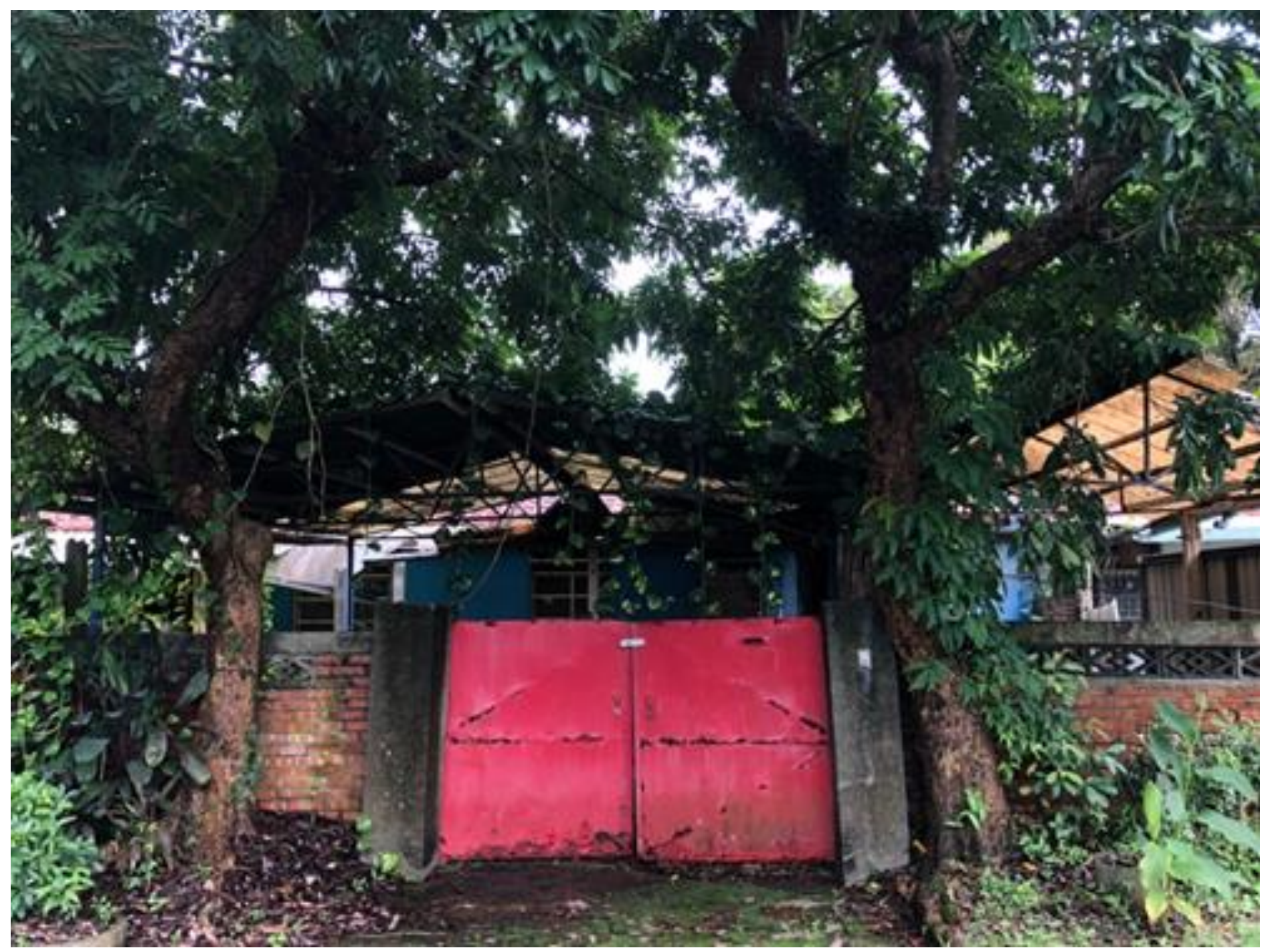

Figure 7: Abandoned house in Zhong Xing New Village. Source: Photo by author, 2019 
The waishengren's culture in ZXNV was further cultivated through the period of isolation from 1949-1987, during which cross-strait communications of any kind was forbidden between Taiwan and China. This meant that the first generation had nowhere but their homes in Taiwan. Slowly but surely, they became more and more attached to ZXNV as their only place of belonging in the world, and their identity became much more tied to the village itself. They were the only ones who understood each other's pain of leaving their ancestral homes behind in China and needing to start a new life in Taiwan during this geopolitically tense period that tore many families apart.

The culture of the waishengren is directly linked to the role of the KMT in the Chinese Civil War. Had the KMT not lost the war, they would not have had to retreat with their supporters to Taiwan. This village provided a bubble of linguistic and cultural safety for the waishengren that further isolated them from the rest of Taiwan as the elite in the KMT's government.

\section{Building the First-Generation Identity: Political Belonging}

The politics of Zhong Xing New Village are inextricably linked to the waishengren identity and history. Since waishengren refer to those who had left China at the end of the civil war with the Kuomingtang, this group aligned politically with the KMT. The KMT has always maintained a strong presence in the village, experiencing rather minimal political dissent throughout the last few decades. All of the interviewees from the first generation of residents identified with the KMT when asked about their political affiliations. Many of them benefit greatly from KMT policies and politics.

As a whole, this middle-class, professional group of post-1949 Chinese immigrants can be collectively referred to as the jun-gong-jiao group (軍公教); “jun” meaning military, “gong" referring to government employees, and "jiao" referring to school teachers. In the KMT's attempt to assert political dominance and control over Taiwan post-1949, it

twice expanded the state bureaucracy and created many repetitive sectors at central and provincial levels ... in the days well before industrialization set its foot on Taiwan, jobs in government sectors promised not only high social prestige but also job security and a good salary package. Hence government positions at all levels were highly valued and earnestly pursued at a time of low literacy and of adverse economic circumstances in the 1950s. (Goodman and Robinson 2004, 209)

The jun-gong-jiao group remains one of the most stable voting blocs in favor of the KMT to this day. Because one had to be employed by either the military, government, or school system to live in the village, everyone in ZXNV was a part of this group. Today, the jun-gongjiao is known for voting consistently in favor of KMT policies that protect retirement pensions, universal healthcare, and social security, as well as for KMT positions on social issues such as their stance against LGBTQ+ rights.

Due to the desirability of government positions in the mid-1900s, the KMT wielded incredible economic power and control over employment and therefore over the employees themselves. The lack of political dissent at this time was directly due to the power of the KMT and the alignment of resident opinions with those of the government. The KMT exercised its unbounded power by governing Taiwan under martial law. This era of martial law would not be lifted until 1987. The main purpose of martial law was to preserve the power of the authoritarian government established by the KMT. When I asked my interviewees if they had known that they were living in the martial law era, almost all of them said that they were unaware. One interviewee said that he learned about martial law after it was lifted, and he had joined the military (A. Tsai, interview, September 9, 2019). "When we were kids, we didn't know about [martial law]. The 'law' wasn't implemented in the area. I think the kids who grow up here, we had a lot of freedom and we can say anything" (S. Pan, interview, September 4, 2019).

In fact, they all cited the years between 19601980 as the golden age of the village. The alignment of the golden age of ZXNV and the era of martial law is not a coincidence. During this time, the KMT was able to rule with the greatest amount of absolute control. This 
meant that residents who identified with the KMT felt no changes in their lived experiences and did not feel ostracized for their political and cultural identities. They benefitted directly from the KMT's absolute power and were therefore blissfully unaware of martial law during this time.

Zhong Xing New Village is one of the last places today in Taiwan where the Kuomintang is not only popular but also openly celebrated and glorified. The statue of Chiang Kai-Shek stands proudly on top of the hill in front of the town hall, overlooking the track field and other recreational spaces. One first-generation interviewee remarked in great fondness, "Chiang was our fearless leader, one deserving of the greatest praise and honor" (S. Zhang, interview, August 20, 2019). The positioning of this statue points to the KMT's continuing authority over the village and its residents. Meanwhile, in DPP (Democratic Progressive Party that is pro-Taiwanese Independence) strongholds such as Tainan and Kaohsiung, KMT statues and memorials are regularly vandalized (AFP 2015).

Chiang Kai-Shek's reputation is typically divided among those of Taiwanese origin and the waishengren who arrived after 1949 following the retreat of the KMT. For the waishengren, Taiwan is China and the KMT is the ruling party of both China and Taiwan. However, these immigrants are simultaneously war refugees and colonizers. The large majority of the population living in Taiwan is made up of indigenous people and those who are multigenerationally Taiwanese. The original citizens of Taiwan saw the retreat of the KMT as an invasion of outsiders who were not that interested in Taiwan before it became a necessity. In the eyes of the waishengren, Chiang was an incredible leader, one deserving of the highest glory, praise, and honor as the development of modern Taiwan is largely attributed to Chiang. This is sharply contrasted with the anti-Chiang, anti-KMT rhetoric associated with the pro-Taiwanese independence movement that refers to Chiang as a dictator and a symbol of Taiwan's authoritarian past.

In Zhong Xing New Village, Chiang's statue remains untouched, even on February 28th, the annual anniversary of the beginning of the era of White Terror and martial law in Taiwan (Shattuck 2017; AFP 2015). Many waishengren refer to Zhong Xing New Village as a safe space, one of the few remaining, where their politics and identity are celebrated and protected.

\section{Part 2: Zhong Xing New Village's Second Generation}

The downfall of ZXNV can be attributed to many surface-level factors, such as the lack of opportunities for higher education and employment. Nevertheless, profound transformations in Taiwanese identity itself and the temporality of identity are at the crux of this decline. The physical and tangible decay of ZXNV is an embodiment of the new relationship between Taiwan and globalization. The secondgeneration's large absence embodies this transformation.

The ZXNV second generation's identity is a heterogeneous hybrid of the changing national identity and the stagnant village-specific firstgeneration identity. The irreconcilable tensions between the two made the second generation feel like they had one foot in both but no claim to either. This mobility of identity, bolstered by new economic opportunities elsewhere thanks to globalization, resulted in the mass exodus of the second generation out of ZXNV, thus causing its significant decline. The second generation's identity could not have been predicted by the KMT because it was shaped by the changes in national identity and globalization.

\section{Building the Second-Generation Identity: Goals and Aspirations}

The first generation came to the village, by choice, in search of opportunities for employment, personal growth, or communities. However, the second-generation residents do not have the same need for ZXNV, and they do not feel as emotionally attached to the village as their parents did. Many of them knew from a very young age that they would be leaving and therefore saw this place as transitory and fleeting. All second-generation interviewees cited educational purposes as the primary reason for leaving the village, given that there were no universities in the village. They pursued professional opportunities that were unavailable in the confines of the village, 
especially following the 1980s as opportunities increased abroad and in other cities.

Ms. Tseng noted that there are only two types of people who do not leave the village given that ZXNV's culture and economic, political, and social systems pushed the second generation out, intentionally or otherwise: (1) people who are not good enough academically to get into international universities and graduate programs or who did not have enough money to pursue these goals, and (2) people who were offered a job to stay. In her case, she had always wanted to leave ZXNV and had, in fact, majored in English so that she could leave. However, she was the thirdyoungest child of four, and her older siblings were able to pursue education abroad. When she finished her college degree in Taipei, she did not have the money to leave. She was offered a job to teach English at the Zhong Xing Middle School and decided to return because her father was also having health issues at the time. After her father passed away, she was able to continue living in her family's house because she had become an employee of the government. Her decision to stay in ZXNV was one of necessity, but she considers it to have been a good opportunity. She is an anomaly, one of the few from the second generation of ZXNV residents who stayed (P. Tseng, interview, August 20, 2019).

This assumption that they did not have a future in the village contributed greatly to the lifestyle decisions that second-generation interviewees made later in their lives. One interviewee notes that he never really had friends in the village, as he knew he would be leaving since he was in elementary school. He moved to Taichung for boarding school at 11 years old and then to the United States. He regarded ZXNV as a temporary launching pad for his future (A. Tsai, interview, September 9, 2019).

For Mrs. Sa, she chose to leave ZXNV to pursue her career in dance. She studied dance in college and knew that she wanted to make this her career. After college, she saw that many of her classmates and childhood friends were moving to the United States, and she chose to immigrate for better professional opportunities. She spoke fondly of the village, though her emotional attachment was to the people of the village and not so much the built environment itself. Like other interviewees, most of her friends moved to Taipei, mainland China, or the United States. She said, "I remember the people, not so much the places." Despite being close to her classmates, she did not see the long-term benefits of living there, especially after her parents moved away too (G. Sa, interview, November 3, 2019).

\section{Building the Second-Generation Identity: Language and Culture}

The second-generation interviewees were much more heterogeneous and divided on the subject of language, culture, and political identity. All of the interviewees speak Mandarin, but many also speak Taiwanese and English. Ms. Tseng jokingly remarked that people from ZXNV often spoke Mandarin with a peculiar accent that was the combination of all of the Chinese dialects spoken in the village. She also mentioned how it was necessary for her generation to learn Taiwanese because they sought educational and professional opportunities outside of the village, whereas her parents were satisfied with their stable career working for the provincial government, which only required them to speak Mandarin.

Unlike their parents, the second generation was not ostracized from the rest of Taiwan for being waishengren because they were born in Taiwan. In fact, growing up in ZXNV provided a certain type of social clout within the village, as if someone raised there was raised "right." A lot of elitism surrounded the second generation as they were socio-politically more mobile in the rest of Taiwan. They had political, educational, and economic access to the rest of Taiwan. There were no external forces such as discrimination elsewhere in the country that would have prevented the second generation from leaving the village, and there were also no internal opportunities or appeals keeping them there.

\section{Building the Second-Generation Identity: Political Belonging}

The second generation offered very mixed viewpoints on government and politics in Taiwan. Many of them saw the benefits of the $\mathrm{KMT}$, especially in the policies that employed and protected the first generation. However, 
many of them also identify as Taiwanese, which makes their understanding of national identity more difficult to align with a political party. When asked if he identified as Taiwanese or Chinese, Mr. Tsai said, "half-half, depends on who's asking, I can go either way." This hybridity of identity is unique to the second generation that was linguistically and culturally shaped by the first generation's waishengren identity, but politically influenced by national changes in Taiwan.

Most interestingly, I found that many of the second-generation interviewees were politically apathetic. Their decisions to immigrate were driven by economic rather than political factors. When the second generation became young adults in the 1980s and 1990s, the politics of Taiwan had changed considerably. The Kuomingtang no longer held complete political and economic power, and the seeds of antiKMT political parties were already in place and starting to grow. As Ms. Pan said, the KMT "designed the village for the people who were there at the time, but they did not think about it for the future and then by the time the second generation grew up, there was a different government in place. That's why ZXNV's history is so different-different government, different parties made different policies that affect ZXNV's future" (S. Pan, interview, September 20, 2019). This statement only became truer with time, as politics became increasingly volatile over the last few decades in Taiwan.

\section{Part 3: What Happened to Zhong Xing New Village?}

The original purpose of ZXNV became completely irrelevant in the face of national identity and political transformation. This shift left the waishengren and the citizens of ZXNV behind and contributed greatly to the downfall of a village established on the monolithic foundation of China-centric KMT politics. ZXNV was built to serve the provincial government; however, how can Taiwan be both a nation and a province? President Lee Teng-Hui asked and acted boldly on this question during his administration.

Lee Teng-Hui's presidency was the tipping point for Kuomintang rule in Taiwan. He was appointed as president of Taiwan by the KMT in
1988 and served until 2000. For the first few years of his career, he faced little dissent as opposition parties had not yet fully formed. Lee Teng-Hui won the 1996 election with $54 \%$ of the vote. At the time, the Provincial Government had control over all areas of Taiwanese daily life and a 98.82\% overlap with the national government in geographic jurisdiction. Threatened by the rise in power and status of the Provincial Government, despite only being established in 1947 by the executive branch of the national government, led by James Soong at the time, and fearing that he and the national government would soon be eclipsed, in 1997, President Lee passed a constitutional reform that limited, streamlined, and essentially defunded the Provincial Government (Chang 2017).

Taiwan, as a sovereign nation, cannot have both a national government and a provincial government. The very term "provincial" assumes that Taiwan is but a province of China and not its own nation. President Lee's decision is one of the most decisive pro-Taiwanese independence political moves made in the history of Taiwan. This pro-independence decision came as a shock to the entire Kuomintang party and its supporters. Interviewees commonly referred to President Lee as having 藍皮,綠骨 (lan-pi-lu-gu), which translates to blue skin, green bones. He maintained a façade of being a spokesperson and leader for the KMT (the blue party) and yet, he made consequential policy decisions that aligned with the DPP (the green party).

This decision, bolstered by the unstoppable wave of indigenization and Taiwanization, completely revolutionized the political landscape of Taiwan and effectively rendered Zhong Xing New Village useless.

Before the streamlining took effect, the provincial government had consisted of a legion of 126,356 civil servants working in 551 organizations, including TPG [Taiwan Provincial Government] departments and bureaus, provincial-level cultural institutions, schools and various subsidiary bodies, and also province-owned enterprises ... within only a few years the provincial machine ground to a halt. The number of employees 
at Chunghsing New Village headquarters was drastically reduced from 4,756 just before the Streamlining to 285 in 2000 and to 85 in 2006. (Chang 2017, 41)

ZXNV's entire purpose had been to serve the needs of the Provincial Government and its employees. Without a government, it is an empty shell of buildings and infrastructure. President Lee's decision is the most clear-cut cause for the sharp decline of ZXNV. However, this decision could not have been predicted by the KMT to be the reason for the death of ZXNV because at the time of construction, the KMT was the only force in Taiwan that faced little opposition due to martial law. The fact that this village served such a specific purpose for a specific time and could not evolve with national changes is the reason why it died.

During his administration (2008-2016), President Ma Ying-Jeou of the KMT said that he would rebuild ZXNV and expand Taiwan's highspeed rail system to include ZXNV. But over the course of his administration, he gradually lost power and then the "DPP took away ZXNV's future" (S. Pan, interview, September 20, 2019). In 2018, President Tsai Ing-Wen of the DPP decided to fully erase the provincial government, and thus all agencies and departments that were located in ZXNV were absorbed into the national government in Taipei.

Today, ZXNV government buildings sit empty as their respective departments were transferred to the national government. The sparse population that remains is largely from the first-generation and continues to live in their assigned houses, adjacent to rapidly decaying abandoned buildings. ZXNV's apparent emptiness embodies the historic structures and transformations that led to the migration of its residents.

\section{Conclusion}

Zhong Xing New Village is a story of a designed space wholly shaped by identity and politics. On the surface, ZXNV is a classic example of a planned city that has experienced great depopulation and disinvestment. However, to understand the fate of ZXNV, one cannot ignore the politics of urban planning because its design could not overcome national, societal changes. As Massey (1992) writes, space is not apolitical or atemporal. ZXNV is an example of a space that tried to exist as a static slice of time, but was ultimately fractured by how national politics changed over time. Even the most utopian, meticulous designs are influenced by existing assumptions and cannot account for the unforeseen future threat of national transformations.

ZXNV is proof that garden cities are effective when the population is not just homogenous but also aligned with the ideals of the planner; the goals and identity of this village were once homogenous and well-aligned with the goals and identity of the KMT. The complete regulation of this village is how the KMT manifested its ideology. The golden era of ZXNV was from the 1960s-1980s, a time when the rest of Taiwan was living under strict martial law. This chronological alignment is not a coincidence but evidence that the KMT designed ZXNV with a very specific, homogenous, ideal population in mind. This population embodied the KMT's ideals, and the decline in the number of bodies reflects the slow decline of the KMT regime. During this time, the design worked perfectly-people lived in the places they were designed to live, worked at jobs that were designed to be their jobs, and shopped at the marketplaces that were designed to be marketplaces. This design began to fall apart as the concentrated, authoritarian power of the KMT began to fall apart, and the homogenous identity of the villagers began to unravel as the second generation came of age.

ZXNV's inability to change its purpose with the changing political landscape led to its depopulation and physical decline. This village was planned as an "ideal world" that reflected the KMT's wishful thinking during a particular political moment, and its ultimate demise is like a second loss of the KMT's dream of a united China that they once wished to represent. Zhong Xing New Village had a lot of promise, but the seeds of its own destruction, through the political awakening and liberalization of Taiwan, were also at its core. 


\section{Acknowledgements}

Thank you to Dr. Elizabeth Greenspan and Dr. Elaine Simon, whose support made this project possible from start to finish. I am grateful for their ability to decipher my writing and know what I am trying to say before I even know it myself.

Thank you to my advisor, Dr. Molly McGlone, whose mentorship has been critical to my personal and professional growth and without whom this paper would have been impossible to complete.

And lastly to 中興新村 and to my grandparents, thank you for everything. 


\section{References}

AFP. 2015. "Taiwanese vandals target late leader Chiang Kai-shek's public profiles." South China Morning Post, August 2, 2015. https://www.scmp.com/news/china/policies-politics/ article/1845994/taiwanese-vandals-target-late-leader-chiang-kaisheks.

Anderson, Benedict. 1983. Imagined Communities: Reflections on the Origin and Spread of Nationalism. London: Verso.

Chang, Bi-yu. 2004. "From Taiwanisation to De-sinification." China Perspectives 56: 1-19. https://doi.org/10.4000/ chinaperspectives.438.

Chang, Bi-yu. 2017. Place, Identity, and National Imagination in PostWar Taiwan. London: Routledge Taylor \& Francis Group.

ChinatownConnection.com. 2007. "Taiwanese Society Under Martial Law Remembered." Accessed November 5, 2019. http:// www.chinatownconnection.com/taiwanese-society-martiallaw.htm.

Chu, Yun-han, and Jih-wen Lin. 2001. "Political Development in 20thCentury Taiwan: State-Building, Regime Transformation and the Construction of National Identity." The China Quarterly 165: 102129. www.jstor.org/stable/3451108.

Goodman, David S.G., and Richard Robinson. 2004. The New Rich in Asia: Mobile Phones, McDonald's and Middle-Class Revolution. London: Routledge.

Howard, Ebenezer. 2013. Garden Cities of To-Morrow. London: Routledge.

Low, Setha M. 2017. Spatializing Culture: The Ethnography of Space and Place. Abingdon, Oxon: Routledge.

Makeham, John, and A-Chin Hsiau. 2005. Cultural, Ethnic, and Political Nationalism in Contemporary Taiwan: Bentuhua. New York: Palgrave Macmillan.

Massey, Doreen. 1992. "Politics and Space/Time." New Left Review 196: 65-84. https://newleftreview.org/issues//196/articles/doreenmassey-politics-and-space-time.

Massey, Doreen. 1995. "Places and Their Pasts." History Workshop Journa/39: 182-92. www.jstor.org/stable/4289361. 
Meng-Hsuan, Dominic, and Mau-Kuei Chang. 2010. “Understanding the Nuances of Waishengren." China Perspectives 3: 108-122. https://doi.org/10.4000/chinaperspectives.5310.

Schubert, Gunter. 2012. “Taiwan's Political Evolution from Authoritarianism to Democracy and the Development of CrossStrait Relations." In European Perspectives on Taiwan, edited by Jens Damm and Paul Lim, 66-83. Wiesbaden: Springer VS.

Shattuck, Thomas J. "Taiwan's White Terror: Remembering the 228 Incident." Foreign Policy Research Institute, February 27, 2017. Accessed June 15, 2021. https://www.fpri.org/article/2017/02/ taiwans-white-terror-remembering-228-incident/.

Stockton, Hans. 2002. "National Identity on Taiwan: Causes and Consequences for Political Reunification." American Journal of Chinese Studies 9 (2): 155-78. www.jstor.org/stable/44288704.

Tseng, Katherine Hui-Yi. 2016. "A Constructed Immaginarium: ReContemplating Identity Construction in Taiwan." American Journal of Chinese Studies 23 (2): 221-37. www.jstor.org/stable/44289156.

方泰鈞. n.d. " 凍省20年 解祕中興新村盛轉衰關鍵. " 聯合報. Accessed November 15, 2019. https://udn.com/upf/newmedia/2017_data/ chnv/. 